Physiology

\title{
Phytotoxic and genotoxic effects of silver nanoparticles exposure on germinating wheat seedlings
}

\author{
Candida Vannini ${ }^{\mathrm{a}, *}$, Guido Domingo ${ }^{\mathrm{a}}$, Elisabetta Onelli ${ }^{\mathrm{b}}$, Fabrizio De Mattia ${ }^{\mathrm{c}}$, \\ Ilaria Bruni $^{\mathrm{c}}$, Milena Marsoni ${ }^{\mathrm{a}}$, Marcella Bracale ${ }^{\mathrm{a}}$ \\ a Dipartimento Biotecnologie e Scienze della Vita, Università degli Studi dell' Insubria, Via J.H. Dunant 3, 21100 Varese, Italy \\ b Dipartimento Bioscienze, Università degli Studi di Milano, Via G. Celoria 26, 20133 Milano, Italy \\ c Dipartimento Biotecnologie e Bioscienze, Università degli Studi di Milano Bicocca, Piazza della Scienza 2, 20126 Milano, Italy
}

\section{A R T I C L E I N F O}

\section{Article history:}

Received 3 February 2014

Received in revised form 7 May 2014

Accepted 7 May 2014

Available online 17 May 2014

\section{Keywords:}

Triticum aestivum

Silver nanoparticles

Proteomics

AFLP

TEM

\begin{abstract}
A B S T R A C T
We investigated the effects of 1 and $10 \mathrm{mg} \mathrm{L}^{-1}$ AgNPs on germinating Triticum aestivum L. seedlings. The exposure to $10 \mathrm{mg} \mathrm{L}^{-1}$ AgNPs adversely affected the seedling growth and induced morphological modifications in root tip cells. TEM analysis suggests that the observed effects were due primarily to the release of $\mathrm{Ag}$ ions from AgNPs.

To gain an increased understanding of the molecular response to AgNP exposure, we analyzed the genomic and proteomic changes induced by AgNPs in wheat seedlings. At the DNA level, we applied the AFLP technique and we found that both treatments did not induce any significant DNA polymorphisms. 2DE profiling of roots and shoots treated with $10 \mathrm{mg} \mathrm{L}^{-1}$ of AgNPs revealed an altered expression of several proteins mainly involved in primary metabolism and cell defense.
\end{abstract}

(c) 2014 Elsevier GmbH. All rights reserved.

\section{Introduction}

Engineered silver nanoparticles (AgNPs) are widely used in personal care products, clothing, food, building materials and medical equipment. AgNPs enter natural ecosystems and persist for extended periods of time (Dobias and Bernier-Latmani, 2013). The toxicity of AgNPs has been demonstrated in various prokaryotic organisms and mammalian cell lines (Marambio-Jones and Hoek, 2010). In higher plants, different and conflicting effects of AgNPs have been reported, depending on the intrinsic AgNP properties (size and shape, aggregation state, and surface coatings), experimental system, plant species and developmental stage (Remédios et al., 2012).

AgNPs are able to induce DNA damage in plants, causing the formation of chromatin bridges, stickiness, disturbed metaphase and multiple chromosomal breaks (Kumari et al., 2009; Panda et al., 2011; Patlolla et al., 2012). Recently, a whole-genome cDNA microarray analysis and a proteomic study have provided new insights into the response of Arabidopsis thaliana (Kaveh et al., 2013) and Eruca sativa (Vannini et al., 2013) to AgNPs and $\mathrm{Ag}^{+}$.

In the present study, we combined proteomic, amplified fragment length polymorphism (AFLP), light and transmission electron

\footnotetext{
* Corresponding author. Tel.: +39 033242 1418; fax: +390332 421330 .

E-mail address: candida.vannini@uninsubria.it (C. Vannini).
}

microscopy (LM, TEM) analyses to characterize the molecular and morphological effects of AgNPs on the early phases of wheat (Triticum aestivum L.) germination, an important and vulnerable stage in the angiosperm life cycle. The differences in protein abundance reflect differences in metabolic activity better than differences in gene transcript levels because the latter are not always reflected at protein levels. AFLP is a robust, highly informative DNA fingerprinting method (Vos et al., 1995) that has been successfully employed to measure genotoxic activity caused by environmental pollutants (Muller et al., 2004; Labra et al., 2007; Aina et al., 2007).

At the genome level, AFLP did not reveal an appreciable genotoxic effect of $10 \mathrm{mg} \mathrm{L}^{-1}$ AgNPs on root and shoot cells. However, proteomic and morphologic data indicate that $10 \mathrm{mg} \mathrm{L}^{-1} \mathrm{AgNPs}$ affects the levels of several proteins involved in metabolism, protein synthesis/folding, and stress responses in multiple cellular compartments. Furthermore, microscopy analysis suggests that the overall toxicity of AgNPs is driven primarily by the release of $\mathrm{Ag}$ ions from these nanoparticles.

\section{Materials and methods}

AgNP suspensions and characterization

All experiments were carried out using $10 \mathrm{~nm}$ PVP-AgNPs (Biopure AG10, Nanocomposix, San Diego, CA). All experimental concentrations were prepared by diluting the AgNP stock solution 
$\left(1 \mathrm{gL}^{-1}\right)$ in deionized water. All dilutions were freshly prepared before use.

The shape and the size of PVP-AgNPs were determined by TEM as previously described (Vannini et al., 2013).

\section{Seed treatment}

The seeds (Triticum aestivum L. cv Blasco) were surface sterilized with $10 \%$ sodium hypochlorite solution for $10 \mathrm{~min}$ and then rinsed with distilled water. For each treatment, 100 seeds were soaked for $4 \mathrm{~h}$ in $32 \mathrm{~mL}$ of $1,10 \mathrm{mg} \mathrm{L}^{-1}$ of PVP-AgNPs. Two sets of control samples were grown: in deionized water only and in deionized water supplemented with 1 or $10 \mathrm{mg} \mathrm{L}^{-1}$ of PVP. A filter paper moistened with $5 \mathrm{~mL}$ of test solutions was put into each $100 \times 15 \mathrm{~mm}$ sterilized Petri dish. Fifteen seeds per dish were transferred onto the filter paper. Each concentration point of the treatments was performed six times. All treatments were conducted in triplicate. Dishes were placed for 5 days in the dark under controlled temperature $\left(25 \pm 1^{\circ} \mathrm{C}\right)$. At the end of the exposure, seedlings were washed three times with 0.1 M EDTA and then with MilliQ-water. Length and weight of roots and shoots were measured, separated and immediately frozen at $-80^{\circ} \mathrm{C}$.

\section{Plant Ag content determination}

Ag content was determined by flame atomic absorption spectroscopy (F-AAS; Thermo-Electron Atomic Absorption Spectrometer, Vannini et al., 2013).

\section{Light and transmission electron microscopy (LM and TEM) analysis}

Control and treated root samples ( $2 \mathrm{~mm}$ long) were treated as described in Vannini et al. (2013).

AgNPs were enhanced with QH silver (Nanoprobes) for 4 min as described by the manufacturer. Five plants were analyzed for each type of treatment. All treatments were conducted in triplicate.

\section{DNA extraction and AFLP analysis}

DNA was extracted using the Plant Genomic DNA Miniprep Kit (Sigma-Aldrich), starting from single plantlets treated with 1 and $10 \mathrm{mg} \mathrm{L}^{-1}$ PVP-AgNPs. For each treatment, 5 individuals were analyzed: root and shoot were separated from each plantlets and used for DNA extraction.

For each sample a total of $50 \mathrm{ng}$ of DNA was digested $(2 \mathrm{~h})$ with EcoRI $(1 \mathrm{U})$ and MseI $(1 \mathrm{U})$. The DNA fragments were ligated (with T4-DNA ligase) to EcoRI ( $2.5 \mathrm{pmol})$ and MseI ( $25 \mathrm{pmol})$ adapters in a final volume of $20 \mu \mathrm{L}$. Ligation reaction was performed at $22^{\circ} \mathrm{C}$ for $2 \mathrm{~h}$. This mixture was used as the template in the preamplification reaction containing DNA primers E00 and M00 (Table S1) complementary to the core of the EcoRI and MseI adapters, respectively. The amplification was performed as described in Labra et al. (2003). The PCR products were amplified in a second round with primers containing selective bases (Table S1); this was carried out using primer pairs E32-M38, E32-M40, E38-M38, E38-M40, E38M42. The EcoRI-primer was labeled by using fluorescent 6-carboxy fluorescein (6-FAM) on the 5 nucleotide. The temperature profile for this step was the following: one cycle of $5 \mathrm{~min}$ at $94^{\circ} \mathrm{C}$, followed by 10 cycles of $30 \mathrm{~s}$ at $94^{\circ} \mathrm{C}, 1 \mathrm{~min}$ at $65^{\circ} \mathrm{C}$ (for the first cycle, subsequently reduced each cycle by $1^{\circ} \mathrm{C}$ for the next nine cycles), and $1 \mathrm{~min}$ at $72^{\circ} \mathrm{C}$, followed by 25 cycles of $30 \mathrm{~s}$ at $94^{\circ} \mathrm{C}$, $1 \mathrm{~min}$ at $56^{\circ} \mathrm{C}$ and $1 \mathrm{~min}$ at $72^{\circ} \mathrm{C}$. The PCR was terminated with a final incubation step of $10 \mathrm{~min}$ at $72{ }^{\circ} \mathrm{C}$. The amplified fragments were fractionated and detected with an ABI PRISM 3130 Genetic Analyzer (Applied Biosystems Inc., Foster City, CA, USA) with the data collection software 3.0 (ABI). AFLP fragment analysis was performed with GeneScan Analysis Software 4.0 (ABI) and the data were assembled in binary format. Fragments were resolved using capillary electrophoresis. The percent of polymorphisms among analyzed samples and control ones was estimated.

Supplementary Table S1 can be found, in the online version, at http://dx.doi.org/10.1016/j.jplph.2014.05.002.

\section{Protein sample preparation and two-dimensional IEF/SDS-PAGE}

Roots and shoots from seedlings exposed to $10 \mathrm{mg} \mathrm{L}^{-1}$ PVPAgNPs were homogenized by using mortar and pestle in liquid nitrogen with an addition of sand quartz. Total protein extraction and two-dimensional electrophoresis were performed as previously described (Marsoni et al., 2008). Three independent extractions and three gel replicas for each experimental condition were performed. Protein detection and image analysis were conducted according to Vannini et al. (2013). Only the spots with a fold change of \pm 1.5 and ANOVA $p$-value $\leq 0.05$ were accepted as differentially expressed.

\section{Mass spectrometry analysis}

Selected spots were excised from the 2-D gels, digested and tryptic fragments were analyzed by LC-ESI-MS/MS (liquid chromatography-electrospray ionization tandem mass spectrometry) (Marsoni et al., 2010). Spectra were compared with in situ database by SEQUEST algorithm incorporated in BIOWORKS BROWSER 3.3 software (ThermoFisher Scientific Inc.): search was performed against the Triticum subset database (31,852 entries), obtained from NCBI-nr database (http://www.ncbi.nlm.nih.gov/) by FASTA database utilities tool of BIOWORKS, and, in case of mismatch, against full NCBI-nr database (25,877,237 entries). The searches were carried out as described in Marsoni et al. (2008).

If needed the name of unknown proteins was annotated by protein similarity search performed by alignment analysis against the NCBI-nr database using BLAST (http://blast.ncbi.nlm.nih.gov/ Blast.cgi). For predicting the subcellular localization we used EukmPLoc 2.0 (http://www.csbio.sjtu.edu.cn/bioinf/euk-multi/, Chou and Shen, 2010).

\section{Statistical analysis}

All results were presented as mean of the replicates \pm standard deviations (SD). Differences between treatments for the different measured variables were tested by one-way variance (Anova), followed by Tukey's HSD post hoc test when significant differences were found $(p \leq 0.05)$.

\section{Results}

\section{Effects of AgNPs on wheat seedlings}

All experiments were carried out using commercially manufactured $10 \mathrm{~nm}$ AgNPs coated with PVP to avoid NP aggregation. The mean size of the AgNPs calculated by TEM was $13.2 \mathrm{~nm}$ with $70 \%$ of the particles ranging from 5 to $15.5 \mathrm{~nm}$ (data not shown).

Phytotoxicity was assessed by measuring the effects on germination, shoot and root growth and biomass accumulation relative to unexposed controls. Germination of control samples was $<90 \%$; AgNP treatments did not show any significant effect on the percentage or rate of germination (data not shown). As shown in Fig. 1A and $B$, the root growth was slightly reduced at $1 \mathrm{mg} \mathrm{L}^{-1}$ of AgNPs whereas, the root length of wheat seedlings exposed to $10 \mathrm{mg} \mathrm{L}^{-1}$ of AgNPs were $63 \%$ of the control $(p<0.05)$. Root tip light browning was observed after $10 \mathrm{mg} \mathrm{L}^{-1}$ treatment. The presence of $10 \mathrm{mg} \mathrm{L}^{-1}$ 

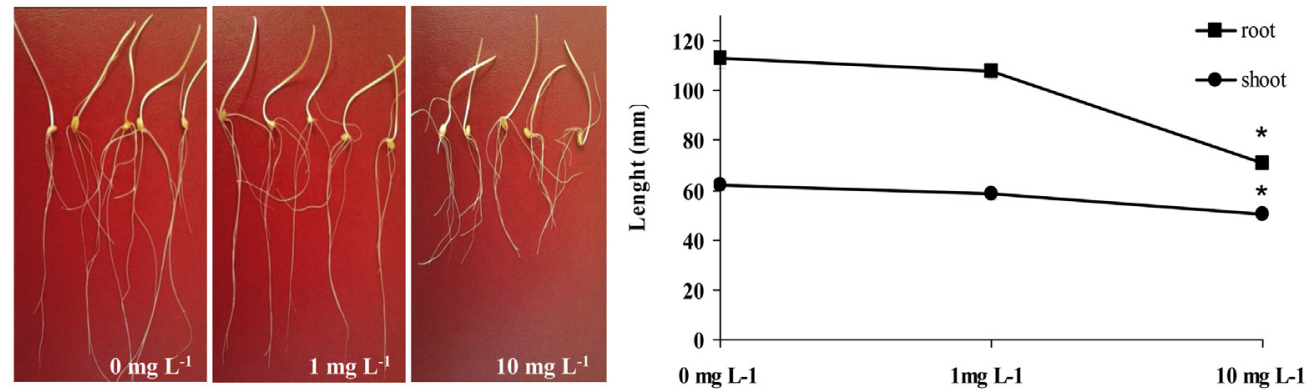

A)

B)

\begin{tabular}{|c|c|c|c|c|}
\hline \multirow{2}{*}{} & \multicolumn{2}{|c|}{$\begin{array}{c}\text { Fresh Weight (FW) } \\
\text { mg /plant }\end{array}$} & Ag Absorption (Rsd\%) \\
ng mg-1
\end{tabular}

C)

Fig. 1. Effects of AgNPs on wheat growth. (A) five days old seedlings germinated at 0,1 and $10 \mathrm{mg} \mathrm{L}^{-1}$ of AgNPs. (B) Root and shoot growth rate $\left({ }^{*} p<0.05\right)$. (C) Fresh weight and $\mathrm{Ag}$ content.

of AgNPs reduced also the shoot length by $15 \%(p<0.05$, Fig. $1 \mathrm{~A}$ and $B)$. Correspondingly, root and shoot fresh weights showed a similar behaviors when treated with AgNPs in comparison with the control (Fig. 1C).

The Ag content in roots and shoots, expressed as $\mathrm{ng} \mathrm{mg}^{-1}$ of dry weight, is shown in Fig. 1C. The amount of Ag uptake was dependent on the quantity of AgNPs suspension. The $96 \%$ of the total $\mathrm{Ag}$ accumulated in the seedlings was associated with the roots. The translocation factor for $\mathrm{Ag}$ concentration in shoots versus $\mathrm{Ag}$ concentration in roots was 0.038 both for 1 and $10 \mathrm{mg} \mathrm{L}^{-1}$ of AgNPs. The values of $\mathrm{Ag}$ measured in wheat treated with $10 \mathrm{mg} \mathrm{L}^{-1}$ of AgNPs, are comparables to those already reported for E. sativa in a similar experimental system (Vannini et al., 2013).

\section{Microscopy}

As roots are the major target of AgNP toxic effect, we investigated by LM and TEM the root morphology of wheat seedling treated with 1 and $10 \mathrm{mg} \mathrm{L}^{-1}$ of AgNPs. In particular, major changes were observed in plastids, vacuole and endoplasmic reticulum (ER) of root cup, meristems and differentiating cells.

Particles associated to the root surface were washed out during inclusion procedures and we induced a low plasmolyze to distinguish nanoparticles associated to cell wall or plasma membrane. AgNPs never enter the root cells and some electron-dense spots were observed only after enhancement procedure. The dark spots were found only associated with the cell wall surface in the outer cells of the root cup in AgNP-exposed plants (Figs. 2B-D and S1-C).

Superficial root cup cells undergo to degradation and their wall was rich in matrix component allowing nanoparticles adsorption. Plasmolyze occurs in a greater extent in AgNP-treated cells since periplasmic spaces appeared larger with respect to the control (Fig. S1-A and B) probably related to the presence of large vacuoles in these cells. Numerous starch grains were contained in columella amyloplasts of control plants which disappear after the exposure to AgNPs (Fig. S1-A-C).
Supplementary Figure S1 can be found, in the online version, at http://dx.doi.org/10.1016/j.jplph.2014.05.002.

In control sample, meristematic cells showed a large nucleus with well structured organelles as mitochondria, golgi apparatus and ER (Fig. S1-D and E). Plastids showed some starch grains which disappeared in treated root (Fig. S1-E and F). After AgNPs treatment, vacuolization occurred in greater extent with respect to root cup cell and the cytoplasm appeared as a thin layer around the cell wall (Fig. S1-E-G).

In control seedlings the differentiating cells showed some small vacuoles and well structured nuclei and organelles (Fig. S1-H). ER was extended and showed more enlarged tubules with respect to meristematic cells (Fig. S1-E and H). After AgNP treatment the vacuolization increased and an extensive swelling was observed in ER whose tubules appeared packaged in regular structures which occupy a large area of the cell (Fig. S1-I and L). ER tubules were surrounded by circular vesicular-like structures that should be cross sections of packaged ER. In this root area one of the most important effects due to $10 \mathrm{mg} \mathrm{L}^{-1}$ of AgNP treatment was the production of a large number of lateral roots primordial. As shown in Fig. S2-B, a lateral root primordium originated very early in the AgNP-exposed root apex. The lateral meristem initiate immediately under the meristematic root apex area in the inner root region corresponding to the new forming style. Differently from primary meristems which appeared highly vacuolated, primordium cells were characterized by typical meristematic morphology showing large nuclei, little vacuole, plastids with some starch grains, numerous mitochondria, wide ER or Golgi and numerous plasmodesmata (Fig. S2-C-E).

Supplementary Figure S2 can be found, in the online version, at http://dx.doi.org/10.1016/j.jplph.2014.05.002.

\section{DNA damage in response to AgNPs}

With the aim of verifying the genotoxic effect of AgNPs on wheat and quantifying DNA damage, AFLP analysis was performed on 

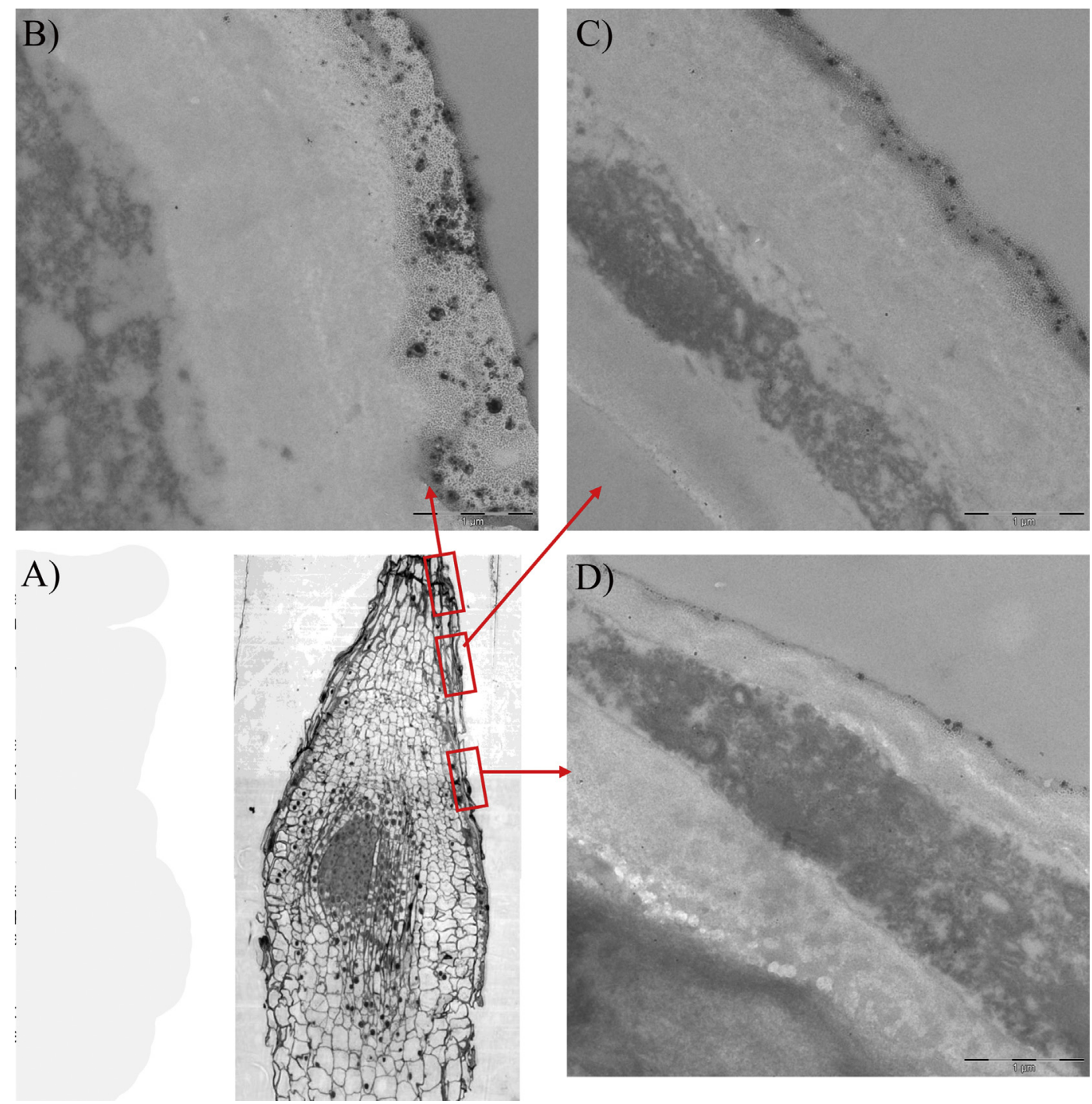

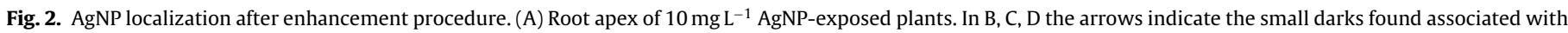
the cell wall surface in the outer cells of the root apex. Magnification bar: $1 \mu \mathrm{m}$.

DNA extracted from controls and from samples treated with 1 and $10 \mathrm{mg} \mathrm{L}^{-1}$ AgNPs. Roots and shoots of each individual were analyzed separately to better evaluate the effect on different plant organs. The AFLP analysis on treated roots revealed a total of 524 DNA bands by using four primer combinations, however only 24 (4.6\%) of which were polymorphic. For treated shoots the total analyzed DNA bands were 534 and 20 of which were polymorphic (3.7\%). Details for each primer combination are given in Table S2. The number of polymorphic bands was very low and equally distributed between treated and control samples and root and shoot portions. The percent of genetic polymorphism detected by AFLP is compatible with the genetic uniformity characterizing $T$. aestivum cultivars (Salunkhe et al., 2013).

Supplementary Table S2 can be found, in the online version, at http://dx.doi.org/10.1016/j.jplph.2014.05.002.

\section{Proteomic changes induced in root and shoot treated with AgNPS}

To shed light on the toxic effects of AgNP treatment we performed a proteomic analysis of roots and shoots treated with $10 \mathrm{mg} \mathrm{L}^{-1}$ of AgNPs, concentration that induces a significant reduction in root and shoot elongation in our experimental system. For both analysis, approximately 800 spots were resolved and detected (Fig. 3). All spots were matched by gel-to-gel comparisons. Differences in the relative abundance (vol\%) of each spot were evaluated by software-assisted analysis. The ANOVA test $(p<0.05)$, coupled with a threshold of 1.5 -fold change in level, revealed 27 and 12 differentially expressed protein spots in roots and shoots treated with AgNP, respectively, relative to unexposed controls. These data indicate that the roots are the major site of proteome changes. The differentially expressed protein spots are marked on the representative 2-DE gels shown in Fig. 3A and B. Among the 27 spots differentially accumulated in AgNP-treated roots, 22 increased and 5 decreased in abundance. In shoots, AgNPs induced the up-regulation of 7 spots and the down-regulation of 5 spots. No identified proteins by LC-ESI-MS/MS were found to be common in the roots and shoots. The identified proteins were classified into different functional categories according to their putative physiological functions. The differentially regulated proteins in AgNP-treated roots mainly belong to the metabolism and cell defense categories. From the predicted localization of differentially expressed proteins it is apparent that, although the cytoplamic proteins are the most represented, proteins are present at other cellular locations also (Tables S3 and S4).

Supplementary Tables S3 and S4 can be found, in the online version, at http://dx.doi.org/10.1016/j.jplph.2014.05.002. 


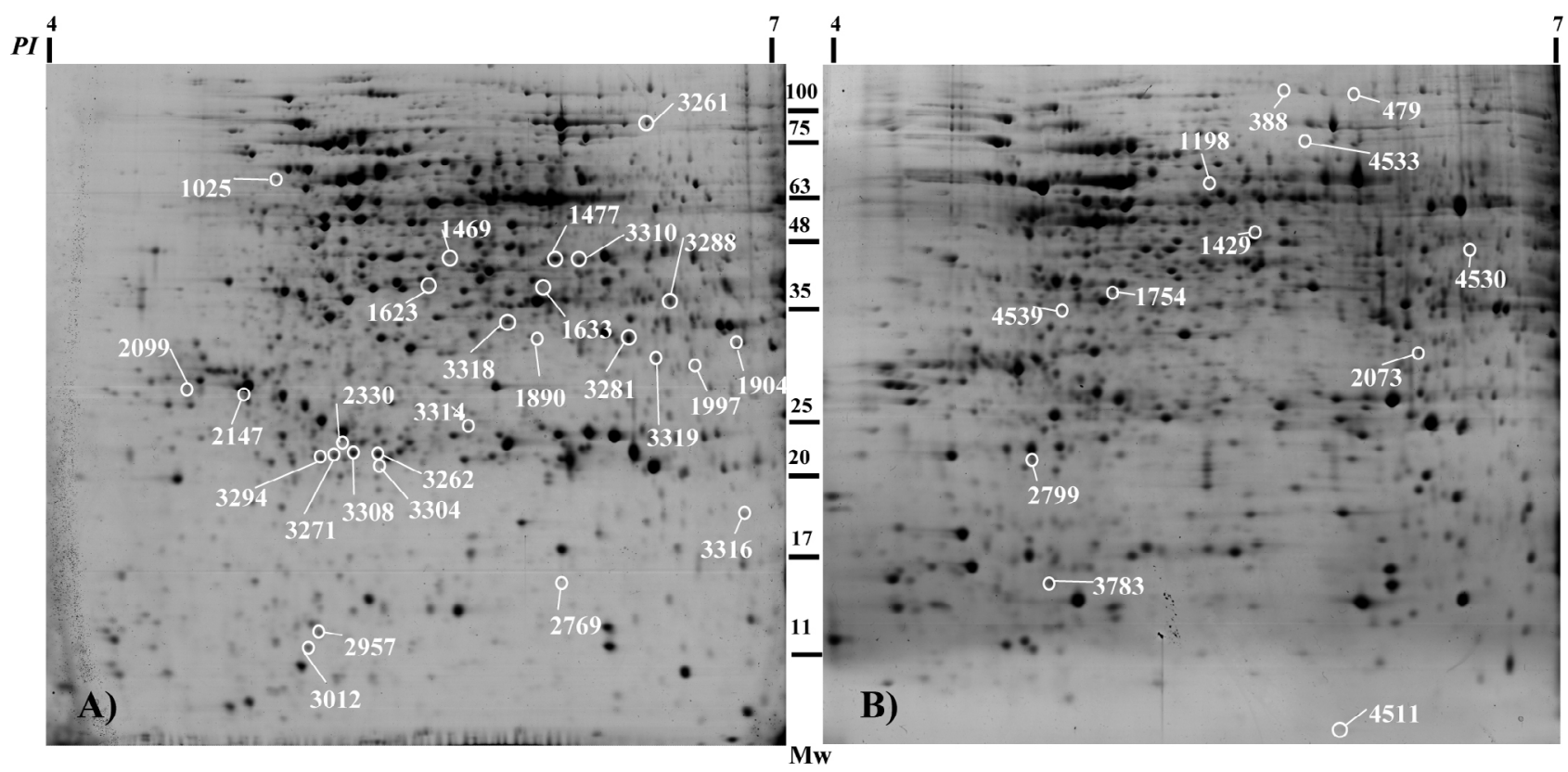

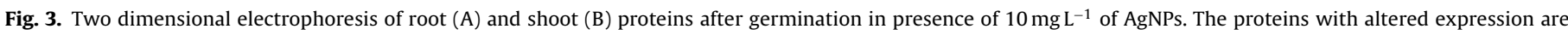
marked.

\section{Discussion}

The treatment with $10 \mathrm{mg} \mathrm{L}^{-1}$ PVP-AgNPs had a toxic effect on the early growth of wheat seedlings.

Other NPs (as $\mathrm{ZnO}, \mathrm{Fe}_{3} \mathrm{O}_{4}, \mathrm{TiO}_{2}, \mathrm{Cu}$ and carbon NPs) were found to negatively affect seedling elongation (Burman et al., 2013; Mushtaq, 2011). In our study the AgNP effect was more evident in the roots. This could be due to the highest accumulation of silver in these organs as previously reported for other plant species (Yin et al., 2011; Wang et al., 2012) and for T. aestivum seedlings using a different experimental system (Dimkpa et al., 2013). We observed a light browning in root tips that had been exposed to $10 \mathrm{mg} \mathrm{L}^{-1}$ AgNPs, which suggests that many of the AgNPs were adsorbed to the root tips. These results are in agreement with our microscopic observations. AgNPs never entered the root cells, and some electron-dense spots were associated with the cell walls of outer root tip cells. These dark deposits were only observed after an enhancement procedure, suggesting that they were smaller than the original particles present in the culture medium. We could not discern whether these spots had arisen from degradation of the original AgNPs or whether they resulted from the nucleation of new NPs as a result of the reduction of Ag ions. The overall data suggest that the AgNP effects observed were primarily due to the Ag ions released by oxidative dissolution of NPs at the root interface in the presence of secreted root metabolites. Similar observations were made on the roots of E. sativa treated with AgNPs in the same experimental system as we employed in the current study; however, in E. sativa, dark spots are also observed inside the cells (Vannini et al., 2013).

Proteomic analysis confirmed the notion that roots are the principal targets of the toxic effects of AgNPs. We observed differences in the number and species of differentially expressed proteins in roots and shoots, which may be related to differences in the amount of Ag that accumulated in these two organs and to different mechanisms used by these organs to respond to AgNP treatment. We identified several differentially expressed proteins that are involved in primary metabolism, suggesting that metabolic adaptation of plants plays an important role in mitigating unfavorable changes in the environment. In AgNP-treated roots, we observed the accumulation of three $\alpha$-amylases and a fructose-bisphosphate aldolase. The accumulation of these enzymes is in agreement with the observation that there was a lower content of amyloplasts in AgNP-exposed root cells than in the control. In AgNP-treated shoots, the levels of two aconitate hydratases increased. The alteration of levels of enzymes involved in energy metabolism may help cells produce more reducing power to facilitate the response to AgNP stress. However, the allocation of more energy to defense responses in roots may also contribute to the reduced growth of seedlings in the presence of AgNPs. The negative impact of AgNP treatment on shoot metabolic activity is also indicated by the downregulation of HCF136 protein, which is essential for photosystem biogenesis, as well as cytochrome b5, which is involved in the electron transfer system in ER membranes.

AgNP treatment caused an increase in the relative level of cytoplasmic malate dehydrogenase (MDH) in roots. Tesfaye et al. (2001) reported that the increase in MDH concentrations in roots of transgenic alfalfa leads to an increase in root exudation of citrate, oxalate, malate, succinate and acetate compared with untransformed control alfalfa plants. We also found that AgNP-treated root cells accumulated a 14-3-3 family protein. The level of a 14-3-3 protein was also reported to be higher in metal $(\mathrm{Al})$ tolerant and lower in Al-sensitive soybean plants (Duressa et al., 2011). Guo et al. (2013) demonstrated that the interaction between 14-3-3 protein and phosphorylated PM $\mathrm{H}^{+}$-ATPase increases the $\mathrm{H}^{+}$pump and citrate secretion in Al-tolerant plants. Moreover, in the presence of AgNPs, wheat roots accumulated a reversibly glycosylated polypeptide (RGP) also involved in cell wall polysaccharide biosynthesis (Dhugga et al., 1997). This result is consistent with TEM observations indicating that the root tip cell walls exposed to AgNPs are rich in matrix components. Overall, these data suggest that as a first line of defense, wheat seedlings exposed to toxic concentrations of AgNPs attempt to prevent or reduce uptake into root cells by restricting metal ions to the apoplast by binding them to the cell wall or to cellular exudates.

TEM observations revealed the development of numerous lateral primordia in AgNP-exposed roots suggesting that AgNPs affect mechanisms controlling lateral root production by the pericycle. Extra branching has previously been observed in wheat roots 
exposed to AgNPs (Dimkpa et al., 2013). The development of the plant root system is affected by multiple internal hormonal cues (De Smet et al., 2006). However, this could probably be due to binding of Ag to ethylene receptor 1 (ETR1) that blocks ethylene responses in dark grown seedling as also reported by McDaniel and Binder (2012) in Arabidopsis. Further this result in low levels of ethylene and consequent promotion of development of lateral primordial as high levels have been reported to inhibit lateral root production in Arabidopsis (Negi et al., 2008).

The levels of two enzymes of the sulfur amino acid biosynthetic pathway, $\mathrm{N}^{5}$-methyltetrahydropteroyltriglutamatehomocysteine-S-methyltransferase (methionine synthase, MS) and S-adenosylmethionine synthetase (SAMS), increased in roots and shoots treated with AgNPs, respectively. MS and SAMS are induced by $\mathrm{Cd}$ in Arabidopsis (Sarry et al., 2006) and $\mathrm{Cr}$ in Zea mays (Labra et al., 2006). These two enzymes are responsible for the conversion of L-homocysteine into L-methionine, and of Lmethionine into S-adenosylmethionine, respectively. Furthermore, S-adenosylmethionine play an important role in polyamine and glutathione (GSH) synthesis. GSH is one of the main molecules responsible for metal sequestration inside the cell. In accordance with these observations, AgNPs caused the accumulation of several glutathione-S-transferases (GST) in wheat roots as also observed in several plant systems under heavy metal stress (Hossain et al., 2012). GST play a role in the conjugation of GSH to cytotoxic compounds affecting their accumulation in the vacuole (Dixon and Edwards, 2010).

$\mathrm{Ag}$ treatment alters the concentration of some peroxidases, chitinases and pathogenesis-related proteins (PRs) involved in stress defense in both roots and shoots. PRs and chitinases are mainly detected in plants exposed to biotic stress. However, altered expression of these proteins in the roots of some plants exposed to different concentrations of metal has been reported (Beáta and Ildikó, 2011). Our results confirm that PR proteins and chitinases are components of the response against metal stress in plants.

To respond to specific stresses, plants must regulate the process of protein synthesis. Accordingly, increased levels of two enzymes involved in protein synthesis in roots were observed in response to AgNPs, i.e., eukaryotic translation initiation factor 5A2 (elF5A) and the $60 \mathrm{~S}$ acidic ribosomal protein PO. The factor IF5A is involved in selective mRNA translation and may play an important role in plant adaptation to changing environmental conditions (Wang et al., 2012). Levels of the cysteine protease triticain $\gamma$ increased in the presence of AgNPs. This vacuolar enzyme plays an important role in storage protein digestion during germination and amino acid production for subsequent plant growth (Muntz et al., 2001). Thus, the accumulation of these proteins may facilitate the translation of mRNA species required for a specific response of roots to AgNPs.

A strong influence of AgNPs on the ER is suggested by both the decreased levels of three ER-resident proteins (Tables S3 and S4) and by the extensive modifications observed in ER structure (Fig. S1-I and L). We previously reported similar results in Eruca sativa treated with AgNPs (Vannini et al., 2013). In mammalian cells, the function of ER chaperones is disturbed by their physical interaction with various metals, including silver, leading to the accumulation of unfolded proteins in the ER, namely, ER stress (Kitamura, 2013).

AFLP is a robust technique for screening DNA damage induced by non-lethal levels of organic and inorganic contaminants (Labra et al., 2003). No relevant differences in the polymorphism number were observed between control and AgNP-treated samples in our AFLP analysis. AgNPs have been shown to induce structural chromosomal aberrations statistically significant in root tip cells of Allium cepa and Vicia fava only at concentrations higher than $10 \mathrm{mg} \mathrm{L}^{-1}$ (Kumari et al., 2009; Patlolla et al., 2012). On the other hand, our proteomic analysis did not demonstrate AgNP-induced changes in the levels of enzymes involved in DNA repair mechanisms.

In summary, our work provides, for the first time, an overall picture of the response of germinating wheat seedlings to $10 \mathrm{mg} \mathrm{L}^{-1}$ $10 \mathrm{~nm}$ PVP-AgNPs, that is, 100-times the highest concentration of $\mathrm{Ag}$ detected in the environment (Essumang and Nortsu, 2008). Some of proteins affected by AgNP exposure represent good candidates for in-depth studies aimed at elucidating the molecular mechanisms underlying plant responses to AgNPs.

\section{Acknowledgements}

This work was partially supported by a grant from Fondazione Banca del Monte di Lombardia (INSUBRIA DBSV-2011).

\section{References}

Aina R, Labra M, Fumagalli P, Vannini C, Marsoni M, Cucchi U, et al. Thiol-peptide level and proteomic changes in response to cadmium toxicity in Oryza sativa L. roots. Environ Exp Bot 2007;59:381-92.

Beáta P, Ildikó M. Plant defense against heavy metals: the involvement of pathogenesis-related (PR) proteins. In: Awaad AS, Kaushik G, Govil JN, editors. Recent progress in medicinal plants. Vol. 31: Mechanism and action of phytoconstituents. New Delhi: Studium Press (India) Pvt. Ltd.; 2011. p. 179-205.

Burman U, Saini M, Kumar P. Effect of zinc oxide nanoparticles on growth and antioxidant system of chickpea seedlings. Toxicol Environ Chem 2013:95:605-12.

Chou K-C, Shen H-B. A New method for predicting the subcellular localization of eukaryotic proteins with both single and multiple sites: Euk-mPLoc 2.0. PLoS ONE 2010;5:e9931.

De Smet I, Vanneste S, Inzé D, Beeckman T. Lateral root initiation or the birth of a new meristem. Plant Mol Biol 2006;60:871-87.

Dhugga KS, Tiwari SC, Ray PM. A reversibly glycosylated polypeptide (RGP1) possibly involved in plant cell wall synthesis: purification, gene cloning, and trans-Golgi localization. Proc Natl Acad Sci USA 1997;94:7679-84.

Dimkpa CO, McLean JE, Martineau N, Britt DW, Haverkamp R, Anderson AJ. Silver nanoparticles disrupt wheat (Triticum aestivum $\mathrm{L}$.) growth in a sand matrix. Environ Sci Technol 2013:47:1082-90.

Dixon DP, Edwards R. Glutathione transferases. Arabidopsis Book 2010;8:e0131.

Dobias J, Bernier-Latmani R. Silver release from silver nanoparticles in natural waters. Environ Sci Technol 2013;47:4140-6.

Duressa D, Soliman K, Taylor R, Senwo Z. Proteomic analysis of soybean roots under aluminum stress. Int J Plant Genomics 2011., http://dx.doi.org/10.1155/2011/282531, 12 pages. Article ID 282531.

Essumang DK, Nortsu BK. Analysis of silver in the water column of the 449 Pra and the Eture estuaries in Ghana. Chem Ecol 2008;24:297-303.

Guo CL, Chen Q, Xiu-Ling Z, Chen X, Zhao Y, Wang L, et al. Al-enhanced expression and interaction of 14-3-3 protein and plasma membrane H+-ATPase is related to al-induced citrate secretion in an Al-resistant Black Soybean. Plant Mol Biol Rep 2013;31:1012-24.

Hossain AM, Piyatida PA, Teixeira da Silva J, Fujita M. Molecular mechanism of heavy metal toxicity and tolerance in plants: central role of glutathione in detoxification of reactive oxygen species and methylglyoxal and in heavy metal chelation. J Bot 2012., http://dx.doi.org/10.1155/2012/872875, Article ID 872875.

Kaveh R, Li YS, Ranjbar S, Tehrani R, Brueck CL, Van Aken B. Changes in Arabidopsis thaliana gene expression in response to silver nanoparticles and silver ions. Environ Sci Technol 2013;47:10637-44.

Kitamura M. The unfolded protein response triggered by environmental factors. Semin Immunopathol 2013;35:259-75.

Kumari M, Mukherjee A, Chandrasekaran N. Genotoxicity of silver nanoparticles in Allium cepa. Sci Total Environ 2009:407:5243-6.

Labra M, Di Fabio T, Grassi F, Regondi SMG, Bracale M, Vannini C, et al. AFLP analysis as biomarker of exposure to organic and inorganic genotoxic substances in plants. Chemosphere 2003:52:1183-8.

Labra M, Gianazza E, Waitt R, Eberini I, Sozzi A, Regondi S, et al. Zea mays L. protein changes in response to potassium dichromate treatments. Chemosphere 2006;62:1234-44

Labra M, Bernasconi M, Grassi F, De Mattia F, Sgorbati S, Airoldi R. Toxic and genotoxic effect of potassium dichromate in Pseudokirchneriella subcapitata detected by microscopi and AFLP analysis. Aquat Bot 2007;86:229-35.

Marambio-Jones C, Hoek ME. A review of the antibacterial effects of silver nanomaterials and potential implications for human and the environment. J Nanoparticle Res 2010;12:1531-51

Marsoni M, Bracale M, Espen L, Prinsi B, Negri AS, Vannini C. Proteomic analysis of somatic embryogenesis in Vitis vinifera. Plant Cell Rep 2008;27:347-56.

Marsoni M, Cantara C, De Pinto MC, Gadaleta C, De Gara L, Bracale M, et al. Exploring the soluble proteome of Tobacco Bright Yellow-2 cells at the switch towards different cell fates in response to heat shocks. Plant Cell Environ 2010:33:1161-75.

McDaniel BK, Binder BM. Ethylene receptor 1 (ETR1) is sufficient and has the predominant role in mediating inhibition of ethylene responses by silver in Arabidopsis thaliana. J Biol Chem 2012;287:26094-103. 
Muller LAH, Lambaerts M, Vangronsveld J, Colpaert V. AFLP-based assessment of the effects of environmental heavy metal pollution on the genetic structure of pioneer populations of Suillus luteus. New Phytol 2004;164: 297-303.

Muntz K, Belozersky MA, Dunaevsky YE, Schlereth A, Tiedemann J. Stored proteinases and the initiation of storage protein mobilization in seeds during germination and seedling growth. J Exp Bot 2001;52:1741-52.

Mushtaq YK. Effect of nanoscale $\mathrm{F}_{3} \mathrm{O}_{4}, \mathrm{TiO}_{2}$ and carbon particles on cucumber seedlings germination. J Environ Sci Health 2011;46:1732-5.

Negi S, Ivanchenko MG, Muday GK. Ethylene regulates lateral root formation and auxin transport in Arabidopsis thaliana. Plant J 2008;55:175-87.

Panda KK, Achary MM, Krishnaveni R, Padhi BK, Sarangi SN, Sahu SN, et al. In vitro biosynthesis and genotoxicity bioassay of silver nanoparticles using plants. Toxicol In Vitro 2011;25:1097-105.

Patlolla AK, Berry A, May LB, Tchounwou PB. Genotoxicity of silver nanoparticles in Vicia faba: a pilot study on the environmental monitoring of nanoparticles. Int J Environ Res Public Health 2012;9:1649-62.

Remédios C, Rosrio F, Bastos V. Environmental nanoparticlesinteractions with plants: morphological, physiological, and genotoxic aspects. J Bot 2012., http://dx.doi.org/10.1155/2012/751686.
Salunkhe A, Tamhankar S, Tetali S, Zaharieva M, Bonnett D, Trethowan R, et al. Molecular genetic diversity analysis in emmer wheat (Triticum dicoccon Schrank) from India. Gen Res Crop Evol 2013;60:165-74.

Sarry JE, Kuhn L, Ducruix C, Lafaye A, Junot C, Hugouvieux V, et al. The early responses of Arabidopsis thaliana cells to cadmium exposure explored by protein and metabolite profiling analyses. Proteomics 2006;6:2180-98.

Tesfaye M, Temple SJ, Allan DL, Vance CP, Samac DA. Overexpression of malate dehydrogenase in transgenic alfalfa enhances organic acid synthesis and confers tolerance to aluminum. Plant Physiol 2001;127:1836-44.

Vannini C, Domingo G, Onelli E, Prinsi B, Marsoni M, Espen L, et al. Morphological and proteomic responses of Eruca sativa exposed to silver nanoparticles or silver nitrate. PLOS ONE 2013;8:1-8.

Vos P, Hogers R, Bleeker M, Reijans M, Lee TV, Hornes M, et al. AFLP: a new technique for DNA fingerprinting. Nucleic Acids Res 1995;23:4407-14.

Wang L, Xu C, Wang C, Wang Y. Characterization of a eukaryotic translation initiation factor 5A homolog from Tamarix androssowii involved in plant abiotic stress tolerance. BMC Plant Biol 2012;12:118-24.

Yin L, Cheng Y, Espinasse B, Colman BP, Auffan M, Wiesner M, et al. More than the ions: the effects of silver nanoparticles on Lolium multiflorum. Environ Sc Technol 2011;45:2360-7 